\title{
Three Dimensional Simulation of the Baneberry Nuclear Event
}

\author{
I. N. Lomov, T. H. Antoun, J. Wagoner, J. T. Rambo
}

This article was submitted to

13th American Physical Society Topical Conference on Shock Compression of Condensed Matter, Portland, OR, July 20-25, 2003

\section{July 16, 2003}

lawnence

Lumermatse

National

Lalmatory

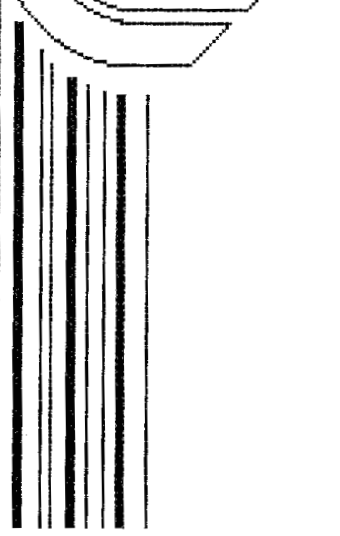




\section{DISCLAIMER}

This document was prepared as an account of work sponsored by an agency of the United States Government. Neither the United States Government nor the University of California nor any of their employees, makes any warranty, express or implied, or assumes any legal liability or responsibility for the accuracy, completeness, or usefulness of any information, apparatus, product, or process disclosed, or represents that its use would not infringe privately owned rights. Reference herein to any specific commercial product, process, or service by trade name, trademark, manufacturer, or otherwise, does not necessarily constitute or imply its endorsement, recommendation, or favoring by the United States Government or the University of California. The views and opinions of authors expressed herein do not necessarily state or reflect those of the United States Government or the University of California, and shall not be used for advertising or product endorsement purposes.

This is a preprint of a paper intended for publication in a journal or proceedings. Since changes may be made before publication, this preprint is made available with the understanding that it will not be cited or reproduced without the permission of the author. 


\title{
THREE DIMENSIONAL SIMULATION OF THE BANEBERRY NUCLEAR EVENT
}

\author{
Ilya N. Lomov, Tarabay H. Antoun, Jeff Wagoner, John T. Rambo
}

Lawrence Livermore National Laboratory, Livermore, California 94550, USA

\begin{abstract}
Baneberry, a 10-kiloton nuclear event, was detonated at a depth of $278 \mathrm{~m}$ at the Nevada Test Site on December 18, 1970. Shortly after detonation, radioactive gases emanating from the cavity were released into the atmosphere through a shock-induced fissure near surface ground zero. Extensive geophysical investigations, coupled with a series of $1 \mathrm{D}$ and $2 \mathrm{D}$ computational studies were used to reconstruct the sequence of events that led to the catastrophic failure. However, the geological profile of the Baneberry site is complex and inherently threedimensional, which meant that some geological features had to be simplified or ignored in the 2D simulations. This left open the possibility that features unaccounted for in the 2D simulations could have had an important influence on the eventual containment failure of the Baneberry event. This paper presents results from a high-fidelity 3D Baneberry simulation based on the most accurate geologic and geophysical data available. The results are compared with available data, and contrasted against the results of the previous $2 \mathrm{D}$ computational studies.
\end{abstract}

\section{INTRODUCTION}

Baneberry was a 10-kiloton underground nuclear test (UGT) conducted at a depth of $278 \mathrm{~m}$ in hole U8d at the Nevada Test Site on December 18, 1970. About 3.5 minutes after detonation, radioactive gases and debris began venting through a fissure that had occurred earlier near surface ground zero [1]. Extensive 2D computational studies of the event were performed [2]. Unfortunately, the Baneberry site has a complex geology and many simplifications had to be made in order to fulfill the geometric assumptions of $2 \mathrm{D}$ calculations. Recent advances in computational capabilities and computer codes made it possible to perform 3D simulations of the event using all the available geological data. The investigation was performed using the LLNL code GEODYN, a parallel transient Eulerian finite volume code with constitutive models that are well suited for analyzing the dynamic response of geologic media. The calculation demonstrated that interaction of the shock wave with several undesirable features of the Baneberry site led to the formation of a continuous damaged region that connected the working point to the surface fissure where the vent was first observed. This damaged region is a likely path for the radioactive gases emanating from the cavity to reach the surface.

\section{BANEBERRY GEOLOGY}

A high-resolution model of the Baneberry geology is shown in Figure 1. This model was constructed using EarthVision $®$, a commercial software package for 3D geologic model building and visualization. The model was developed based on information from the boreholes represented by the blue lines in Fig. 1. Some of these boreholes were pre-shot exploratory boreholes while others were associated with neighboring UGTs that preceded Baneberry. Still others were post-shot boreholes drilled to collect data to aid in the investigation into the cause of the Baneberry containment failure. The model shown in Fig. 1 is the most accurate geologic model available of the Baneberry site, and includes features of the site 
believed to have contributed to the formation of the fissure:

- Three major faults with appreciable differential displacement near the working point (WP);

- Multilayered geology containing two layers of porous alluvium, a tuff layer and a hard paleozoic layer;

- A clay-altered tuff region in the vicinity of the WP. This region was modeled as two discrete regions with $50 \%$ and $20 \%$ clay content, with the $50 \%$ clayey region fully contained within the $20 \%$ region.
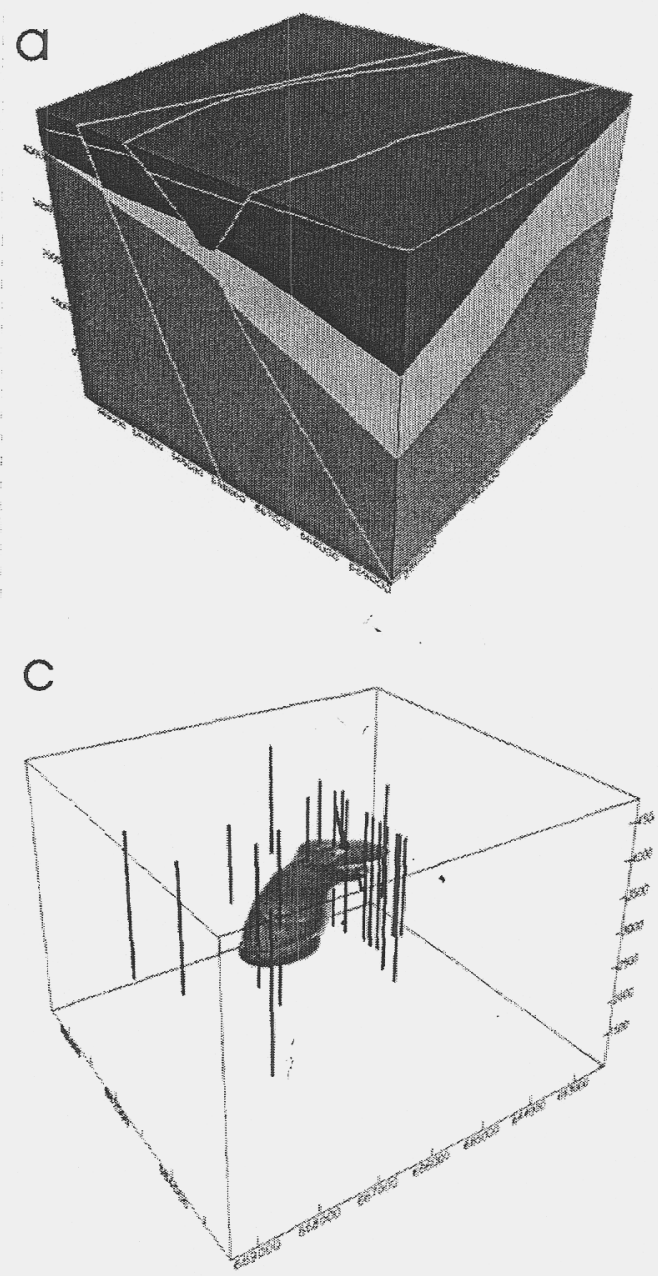

The EarthVision $®$ geologic model was remapped on a rectangular grid with volume fractions to perform the $3 \mathrm{D}$ Baneberry containment calculation.

\section{NUMERICAL METHOD}

The 3D Baneberry simulations were performed using GEODYN, a 3D Eulerian Gudonov code with adaptive mesh refinement capabilities. It is a parallel code that has been used on many of LLNL's ASCI computing platforms to simulate a
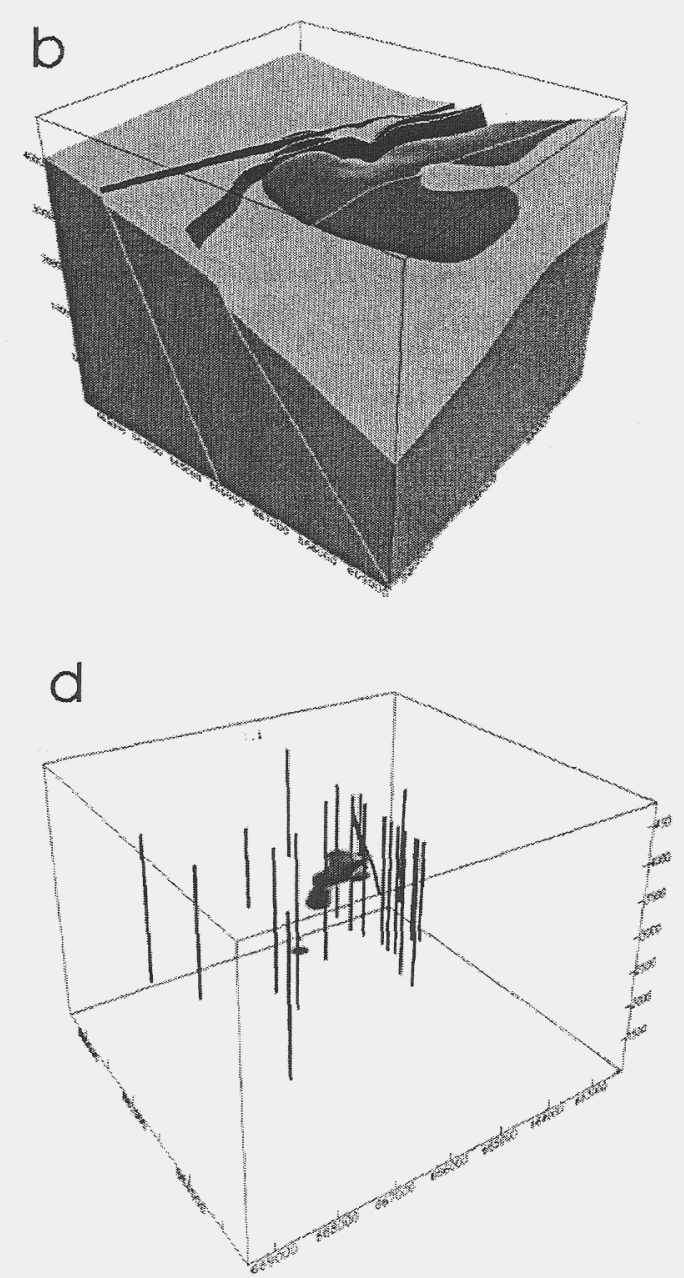

FIGURE 1. EarthVision ${ }^{\circledR}$ geologic model of Baneberry site. a) Overall geology b) Geology with the top alluvium layer removed c) The layer of tuff with clay content greater then $20 \%$ d) The layer of tuff with clay content greater then $50 \%$ 
wide range of problems involving the interaction of shock waves with geologic media. Among its many features, GEODYN includes a high order interface reconstruction algorithm, and an advanced thermodynamically consistent constitutive model that incorporates many of the salient features of the dynamic response of geologic media. Because it uses a Eulerian formulation, GEODYN is able to handle the severe material deformation in the nearsource region. Material interfaces in the code are treated using a volume fraction approach with a piecewise linear interface reconstruction method. A high-order Godunov solver is used in singlematerial regions. Material strength is described within the framework of the general, fully nonlinear theory of plasticity. Porous compaction and dilatancy are also included in the formulation, which on the whole is thermomechanically consistent with the second law of thermodynamics. The code is implemented in the BoxLib framework originally developed at Berkeley National Laboratory. BoxLib provides a framework for efficient adaptive mesh refinement, and is fully capable of massively parallel execution.

\section{MATERIAL MODELS}

Properties for the six different geologic materials in the simulation were taken from the work of Glenn et. al. [2]. The incipient porosity compaction model, pressure dependent yield surface and the equation of state were transferred unmodified. The main challenge was to adapt a directional tensile failure model with features similar to those of the model used in the 2D Lagrangian calculations. A model that uses explicit cracks to represent tensile failure, like the one used in the 2D Lagragian simulations, is difficult to use in a Eulerian framework due to difficulties in advecting crack damage variables, including the orientation of the fracture triad. Hence a new model for directional tensile failure was developed within the framework of a properly invariant nonlinear thermomechanical theory [3]. The new model introduces a second order damage tensor, which admits damage-induced anisotropy, and allows weakening due to tension applied in one direction, without weakening to subsequent tension applied in perpendicular directions. This damage tensor can be advected using standard methods in computer codes. Porosity is used as an isotropic measure of volumetric void strain and its evolution is influenced by tensile failure. The rate of dissipation due to directional tensile failure takes on a particularly simple form, which can be analyzed easily. Specifically, the model can be combined with general constitutive equations for porous compaction and dilation, as well as viscoplasticity. A robust non-iterative numerical scheme for integrating these evolution equations was implemented. An advantage of the new model is that it has a very limited number of parameters and they can be directly related to the parameters of the Lagrangian tensile failure model used in past containment calculations. This continuum multidirectional tensile damage model was successfully used to simulate damage development in an explosively loaded Danby marble specimen. The results of this study are presented I $n$ a companion paper in these proceedings [4].

\section{SIMULATION RESULTS}

The Baneberry simulation described here was performed using 648 CPUs on the MCR cluster at LLNL. It took about three days, or approximately $50000 \mathrm{CPU}$ hours, to complete the simulation. The computational grid consisted of $360 \times 360 \times 288$ cells (about 38 million cells) with a $2.78-\mathrm{m}$ spatial resolution. It took 3000 time steps to advance the calculation to 0.85 seconds, at which time the stress waves within the computational domain had attenuated sufficiently that all inelastic processes, including tensile damage accumulation, had ceased.

We interpret tensile damage as a necessary condition for the formation of the vent path. Figure 2 represents volume rendering of the eigenvalues of the damage tensor due to tensile failure. As the figure indicates, there are three regions where damage accumulation is most pronounced: the weak clayey region in the vicinity of the working point, the weak material within each of the three faults, and a cone-shaped spalled region near surface ground zero. These three damaged regions are connected to one another, thereby forming a continuous damaged region that connects the WP to the surface fissure where the radioactive release was first detected.

Within the context of the modeling approach presented here, tensile damage accumulation is a 

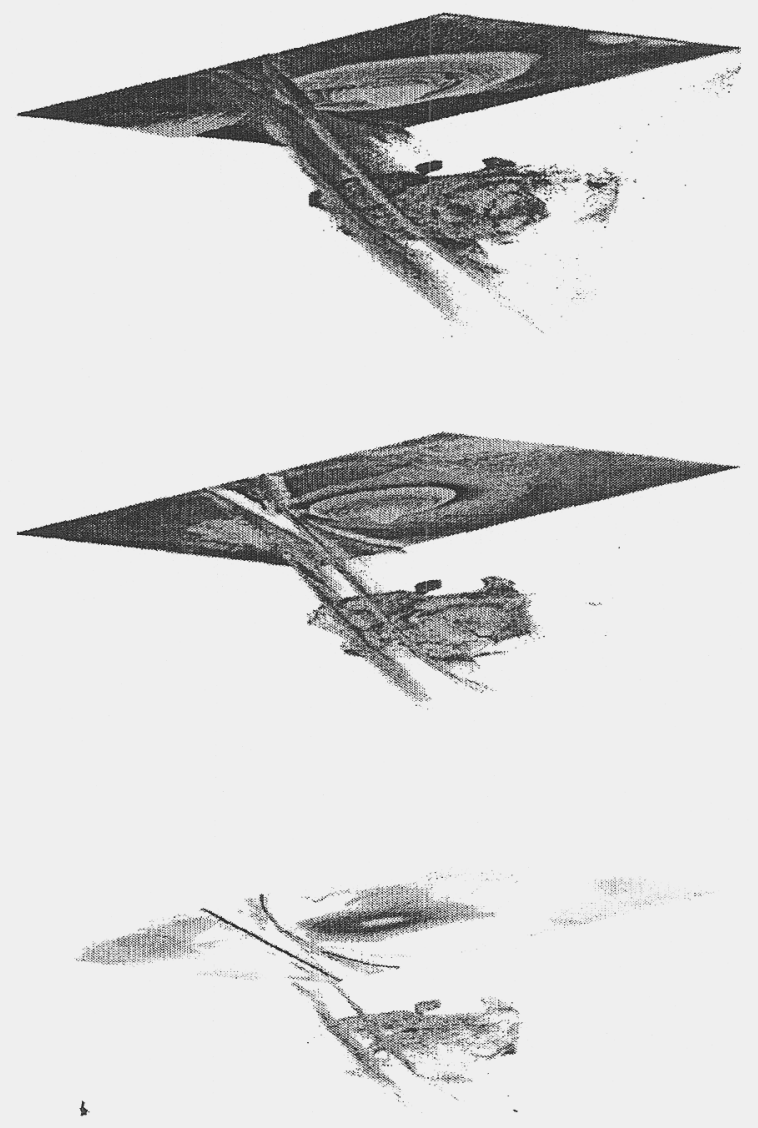

FIGURE 2. Volume rendering of maximum, intermediate and minimum eigenvalues of the damage tensor at the end of the simulation. Vent path formation is clearly indicated.

necessary, but not necessarily a sufficient indicator of containment failure. Damaged regions are generally more porous and as such more permeable than the surrounding medium. However, when a damaged zone is subjected to compression normal to the crack surface, recompaction occurs and the once permeable damaged zone can become much less permeable. For this reason, a complete assessment of containment requires a time-resolved examination of the stress field in the region connecting the WP to the ground surface, in addition to an examination of the evolution of damage. Such an analysis is complex and requires advanced visualization tools that are currently under development. We expect these tools to reach a state of maturity that allows for a complete containment assessment in the near future. In the mean time, a limited analysis of the stress field around the Baneberry cavity has been performed. This analysis indicates a loss of spherical symmetry early in the simulation due to wave reflections in the region near the cavity. The reflections are most prominent at the interface between the hard Paleozoic layer and the much weaker tuffaceous layer, which also has a much lower impedance than the Paleozoic. The lack of symmetry, especially at late time, inhibits the formation of a residual compressive stress field around the cavity. Such a stress field, generally called a stress cage, has been observed experimentally, and is viewed as being an important component of a well contained UGT [1]. The results of the present 3D Baneberry simulation do not support the formation of a residual compressive stress field around the WP. In this regard the results of the 3D simulation are also consistent with those obtained earlier in the 2D computational examination of the Baneberry event [2].

\section{ACKNOWLEDGMENTS}

This work was performed under the auspices of the U.S. Department of Energy by the University of California, Lawrence Livermore National Laboratory under contract No. W-7405-Eng-48.

\section{REFERENCES}

1. B.K. Crowley. "Baneberry Vent Re-examined", Internal Document, UOPKA 71-1, Lawrence Livermore National Laboratory

2. H.D. Glenn, J.T. Rambo, R.W. Terhune, "Calculational study of Baneberry", in Shock Waves in Condensed Matter-1983, edited by J.R.Asay et al., AIP Conference Proceedings 505, New York: American Institute of Physics, 1984, pp. 509-513.

3. M.B. Rubin, I. Lomov, 2003, " A thermodynamically consistent large deformation elastic-viscoplastic model with directional tensile failure," Int. J. Solids and Structure, Vol.40, No. 17, pp.1841-1871.

4. T.H. Antoun, I.N. Lomov, " Simulation of a Spherical Wave Experiment in Marble Using a Multidirectional Damage Model ", These proceedings 